\section{Radiation induced degradation of Congo red dye: a mechanistic study}

\begin{abstract}
Synthetic dyes are persistent pollutants with poor biodegradability. The present study is about the degradation of direct Congo red dye in aqueous media using the Co-60 gamma radiation source. The experimental conditions such as gamma-ray absorbed doses, amount of oxidant $\left(\mathrm{H}_{2} \mathrm{O}_{2}\right)$ and $\mathrm{pH}$ conditions were evaluated. The $\lambda_{\max }$ of dye solution was noted as $498 \mathrm{~nm}$, and then, decrease in absorbance and reduction in chemical oxygen demand (COD) were examined. The complete colour removal of dye was observed at $5 \mathrm{kGy}$, while a significant COD removal was observed at $15 \mathrm{kGy}$ gamma-ray absorbed dose in conjunction with oxidant for $50 \mathrm{mg} / \mathrm{L}$ concentration. It was found that $\mathrm{pH}$ has no influence on degradation efficiency. A possible degradation pathway was proposed. The radiolytic end products were monitored by Fourier transform infrared (FTIR) and gas chromatography coupled with mass spectrometry (GC-MS) to explore the degradation mechanism. It was imperative to study the oxidative degradation pathway to provide directions for potential applicability of advanced oxidation process (AOP) in industrial wastewater treatment.
\end{abstract}

Keywords: Congo red $\bullet$ radiolytic product $\bullet$ irradiation $\bullet$ advanced oxidation process

M. Muneer ${ }^{\bowtie}$, M. Saeed, A. Haq, M. K. Khosa,

M. A. Jamal, S. Ali

Department of Chemistry

Government College University

Faisalabad, Pakistan

E-mail: majid.chemist@yahoo.com

\section{A. Bhatti}

Department of Chemistry

University of Agriculture

Faisalabad, Pakistan

Received: 20 April 2018

Accepted: 4 March 2019

\section{Introduction}

The synthetic dyes have been utilized extensively in various industries such as dyes, paper, textile, plastics, leather, food and cosmetic. The application of dyes in industries imposed a threat to surface as well as ground water [1-3]. The azo dyes are toxic, non-biodegradable and have been frequently utilized in the textile sector due to their characteristics such as resistance toward light, temperature, washing and better colour fastness ability $[4,5]$. The wastewater expelled may contain toxic by-products of textile auxiliaries due to low fixation on fabrics and get mixed in water bodies $[6,7]$.

Access to pure water is the primary need for human beings. The environment faces threat as a result of rapid industrial growth. The industrial effluents are resistant toward usual treatments options and have disadvantages of ineffective treatment, sludge formation, non-destructive method and phase change $[8$, 9]. There is a need of some effective treatment technologies for degradation of pollutants to resolve the issues associated with conventional methods. The advanced oxidation processes (AOPs) are characterized due to generation of hydroxyl radicals $(\bullet \mathrm{OH})$. These methods have gained attention and are thought to be effective for degradation/mineralization of complex organic compounds or industrial effluents [10-12]. 


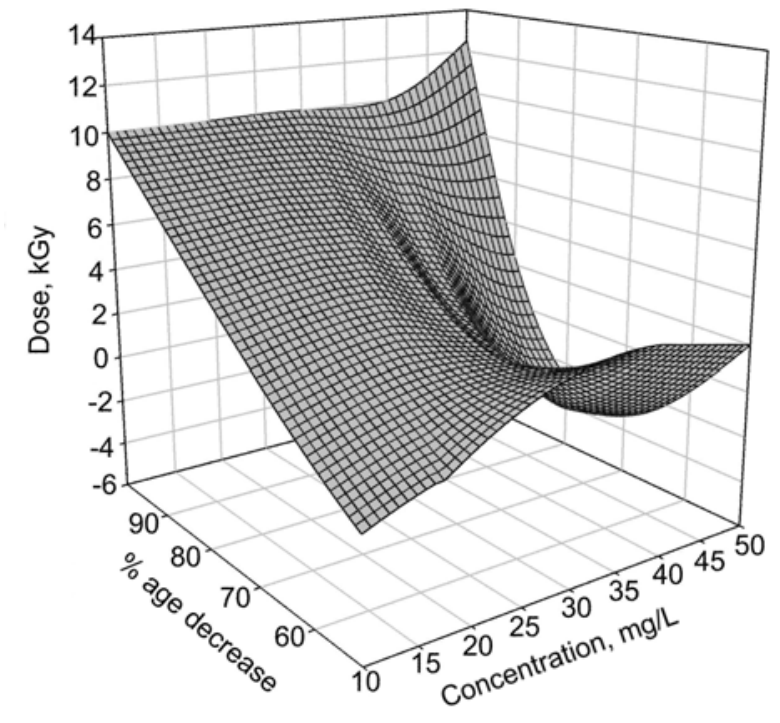

Fig. 1. Effect of gamma radiation on absorbance of direct Congo red dye.

AOPs are promising for the degradation of pollutants such as pesticides, antibiotics, dyes and pharmaceutical wastes. The hydroxyl radicals generated by gamma radiation in the presence of hydrogen peroxide are currently utilized for radiolytic degradation of pollutants and industrial/domestic effluents [13, 14].

Very little literature is available regarding the current study. This work aimed to treat Congo red dye solutions by gamma radiation in the presence of oxidants. The study of radiolytic degradation was performed by UV/Vis, spectroscopy, Fourier transform infrared (FTIR) and gas chromatography-mass spectrometry (GC-MS) analyses along with determination of chemical oxygen demand (COD).

\section{Results and discussion}

\section{Effect of gamma-ray absorbed dose on colour intensity}

The Congo red dye exhibits $\lambda_{\max }$ at $498 \mathrm{~nm}$. The decrease in absorbance after gamma-ray treatment was evaluated. The dye solution having a concentration of $10-50 \mathrm{mg} / \mathrm{L}$ was subjected to gamma-ray treatment alone and then treatment in the presence of oxidant. The complete colour removal was observed at $5 \mathrm{kGy}$ as shown in Figs. 1 and 2. The colour removal efficiency of dye solution owe to breakdown of chromophoric group(s), while mineralization occurred due to breakdown of complex structure into simpler fragments $[15,16]$. The $5 \mathrm{kGy}$ gamma-ray absorbed dose is ineffective to destruct the molecule, and this assumption was also proven by analysis of COD: reduction was only $37 \%$ at this absorbed dose even in the presence of oxidant.

When gamma radiation interacts with dilute dye aqueous solution, radicals such as $\mathrm{OH}^{\circ}, \mathrm{H}^{*}$ and $\mathrm{e}_{\mathrm{aq}}^{-}$are generated with minor species. The presence of oxygen resulted in the formation of ${ }^{\circ} \mathrm{O}_{2}^{-}$and hydro-

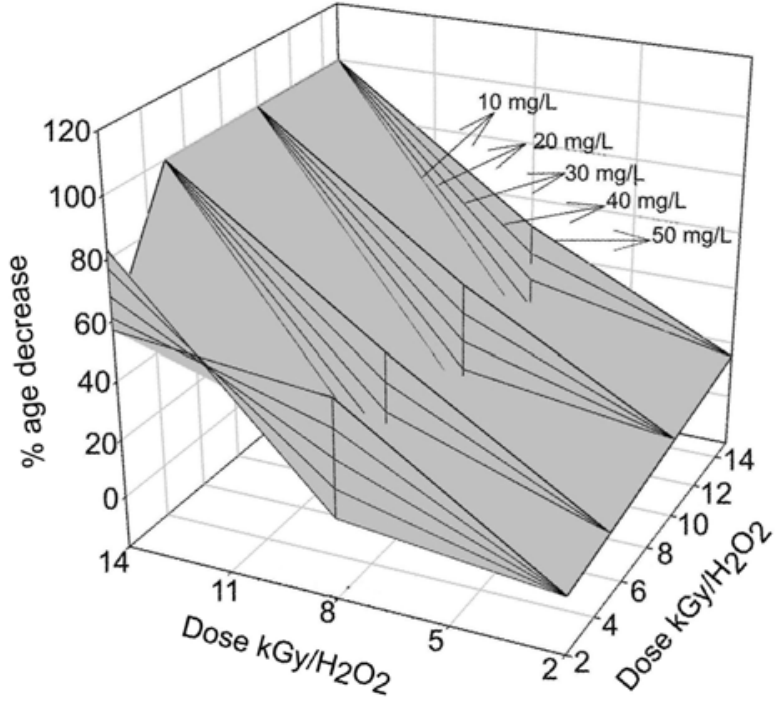

Fig. 2. Effect of gamma radiation in the presence of $\mathrm{H}_{2} \mathrm{O}_{2}$ on absorbance of direct Congo red dye solutions.

peroxy radical ${ }^{\circ} \mathrm{HO}_{2}$. The presence of oxidant $\left(\mathrm{H}_{2} \mathrm{O}_{2}\right)$ promotes the dye bleaching efficiency, scavenges the reducing species $\left(\mathrm{H}^{\cdot}\right.$ and $\left.\mathrm{e}_{\text {aq }}^{-}\right)$and promotes the oxidation process [17].

\section{Effect of gamma-ray treatment on chemical oxygen demand}

As a result of treatment of dye solution, the reduction in COD was due to fragmentation of complex molecule into end product [18]. The noted COD removal was up to $20,24,30$ and $47 \%$ when the dye solutions were treated with $2,5,10$ and 15 kGy gamma-ray absorbed doses, while the decrease in COD was $29,37,45$ and $80 \%$ when the treatment was carried out by gamma ray in the presence of $0.5 \mathrm{~mL}$ of oxidant $\mathrm{H}_{2} \mathrm{O}_{2}$ in $100 \mathrm{~mL}$ of solution as shown in Figs. 3 and 4. The addition of oxidant significantly improved the treatment efficiency and not only scavenged the reducing species but also enhanced $\mathrm{OH}^{*}$ radicals [19]. The attributed fact behind this notion is that decolouration of dye is just destruction of chromophore(s), while COD reduction indicated splitting of dye molecules into lower mass aldehyde, carboxylic acids, $\mathrm{CO}_{2}$ and $\mathrm{H}_{2} \mathrm{O}$ [20] .

\section{FTIR studies}

The FTIR profile of untreated Congo red dye (Fig. 5) shows various functional groups: $3480 \mathrm{~cm}^{-1}$ peak refers to $\mathrm{NH}$ stretching of amine, $2370 \mathrm{~cm}^{-1}$ to $\mathrm{NH}_{2}$ stretching vibration, $1633 \mathrm{~cm}^{-1}$ to $\mathrm{NH}$ bending, $1560 \mathrm{~cm}^{-1}$ to $\mathrm{N}=\mathrm{N}$ stretching, $1510 \mathrm{~cm}^{-1}$ may be to aromatic $\mathrm{C}=\mathrm{C}$ stretching, $1400 \mathrm{~cm}^{-1}$ to asymmetric $\mathrm{CH}$ bending, $1356 \mathrm{~cm}^{-1}$ to $\mathrm{CN}$ bending and $1200 \mathrm{~cm}^{-1}$ may be to CO stretching. The FTIR spectrum of treated dye (Fig. 6) indicates complete degradation of aromatic rings after treatment, but some minor peaks appeared such as $3020 \mathrm{~cm}^{-1}$ attributed 


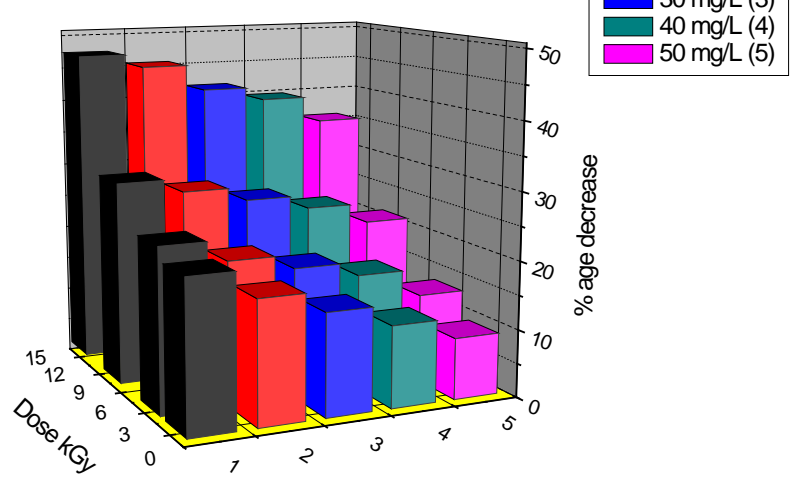

Fig. 3. Effect of gamma radiation on COD reduction of direct Congo red dye.

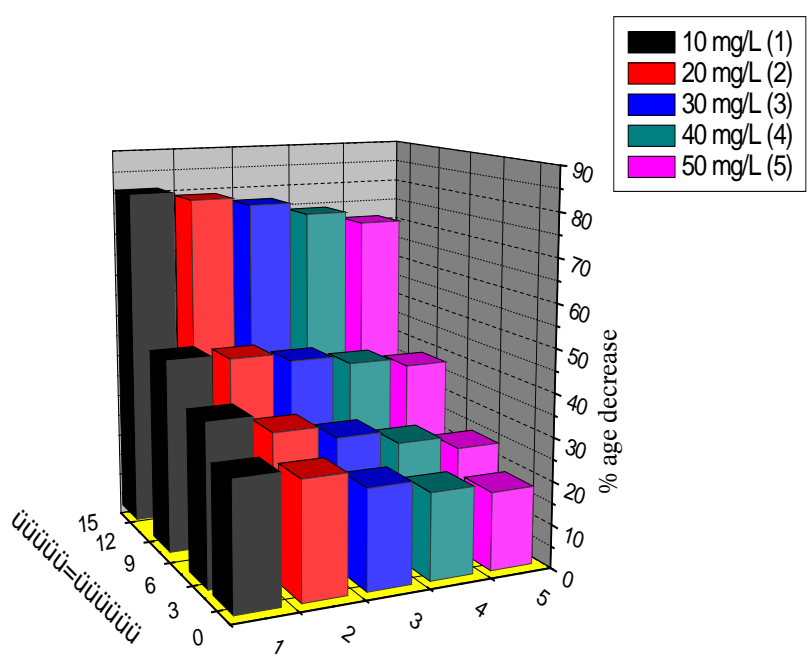

$$
2 \mathrm{O}^{2}
$$

Fig. 4. Effect of gamma radiation in the presence of $\mathrm{H}_{2} \mathrm{O}_{2}$ on COD reduction of direct Congo red dye.

to $\mathrm{CH}$ stretching and $1215 \mathrm{~cm}^{-1}$ corresponding to $\mathrm{CO}$ stretching; the remaining group disappeared in the treated dye sample. It is assumed that dye molecules have been broken through chain oxidation initiated by $\mathrm{OH}^{\cdot}$ radical via destruction of aromatic rings into simpler compounds. The same observations of oxidative degradation of dyes initiated by destruction of N-N bond and then mineralization have also been reported previously [21].

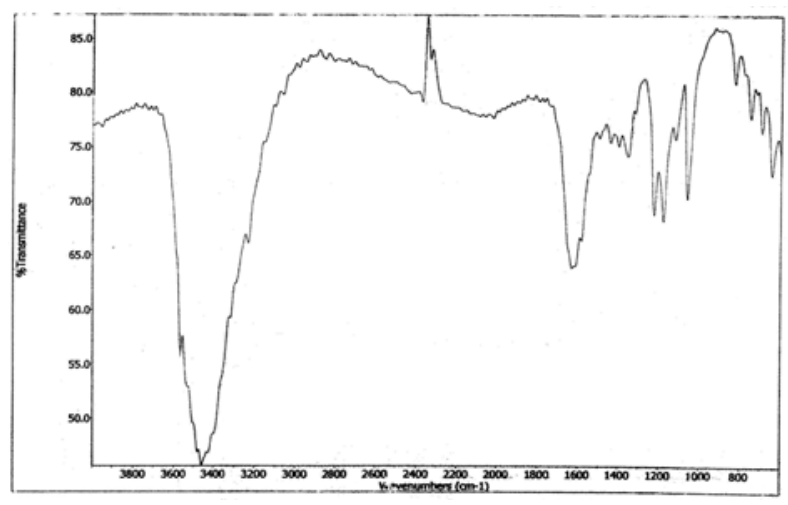

Fig. 5. FTIR profile of unirradiated direct Congo red dye.

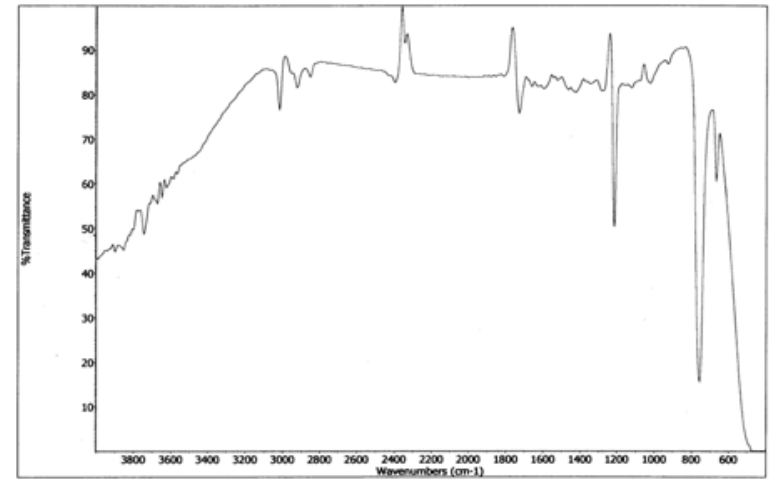

Fig. 6. FTIR profile of treated direct Congo red dye at $15 \mathrm{kGy}$ in the presence of $\mathrm{H}_{2} \mathrm{O}_{2}$.

\section{GC-MS studies}

The GC-MS analyses were performed in order to ensure the degradation in treated samples of Congo red dye. No characteristic peak was recorded in GC-MS spectra except some minor peaks after $15 \mathrm{kGy}$ radiation treatment. On the base of mass spectral fragments in Table 1, a proposed mechanism (Scheme 1) commenced from the removal of azo linkage and breakdown of complex molecule. The further reaction further degraded intermediates into low-molecular weight fragments and then converted them into $\mathrm{CO}_{2}$ and water, and results have harmony with the work of degradation of C.I. Reactive Red 2 [19].

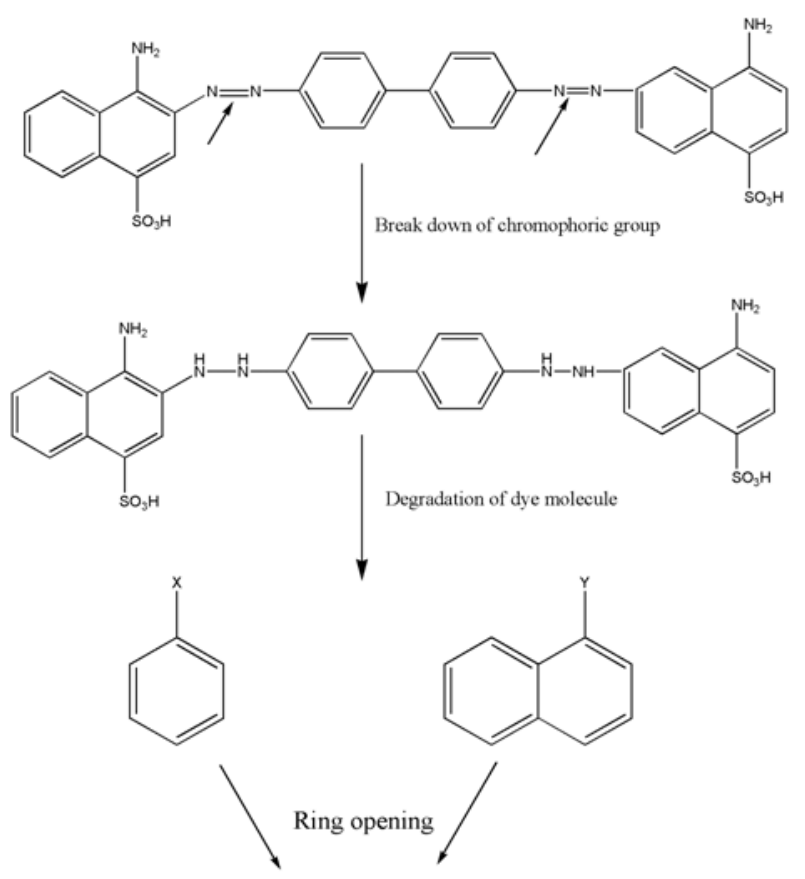

Carboxylic acids, Aldehydes, Alkane

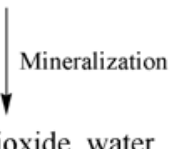

Carbon dioxide, water

Scheme 1. Proposed mechanism for degradation pathway of direct Congo red dye. 
Table 1. Mass spectra analysis of intermediate fragments of direct Congo red dye

\begin{tabular}{cccc}
\hline No. & $\begin{array}{c}\text { Retention } \\
\text { time }\end{array}$ & $\begin{array}{c}\text { Compound identified by MS } \\
\text { (probable) }\end{array}$ & Major ions $(m / z)$ \\
\hline 1 & 17.5 & $n$-hexane decanoic acid & $250,227,213,185,149,129,115,97,83,73,60,55$ \\
2 & 19.3 & octadecanoic acid & $284,255,241,227,185,129,111,83,69,55$ \\
3 & 22.5 & 1,2 -benzenedicarboxylic acid & $167,149,132,121,113,104,83,76,70,57$ \\
10 & 24.5 & 2,6 -di-tert-butyl-4-methyl phenol & $220,190,173,166,149,123,89,65,55$ \\
\hline
\end{tabular}

\section{Experimental}

\section{Chemicals used}

The commercial Congo red dye was procured from the local market. Hydrogen peroxide was purchased from Fluka (Germany). Ethyl acetate, potassium dichromate, ferrous ammonium sulphate, sodium hydroxide and sulphuric acid were provided by Merck (Germany). The solutions and dilution were prepared using triply distilled water.

\section{Radiation treatment of dyes solution}

The irradiation of dye aqueous solutions was performed by Co-60 gamma radiation source available at the Nuclear Institute for Food and Agriculture (NIFA), Tarnab, Peshawar, in Pyrex vials at ambient temperature, while gamma-ray absorbed doses were 2, 5, 10 and $15 \mathrm{kGy}$ alone and then in conjunction with oxidant $\left(\mathrm{H}_{2} \mathrm{O}_{2}\right)$. The optimum amount $0.5 \mathrm{~mL}$ of $\mathrm{H}_{2} \mathrm{O}_{2}(37 \%)$ was added to $100 \mathrm{~mL}$ of dye solution in order to scavenge the reducing species and produce hydroxyl radicals. The dose rate was determined by Fricke dosimetry according to the standard method [22].

\section{Analysis}

\section{Determination of colour intensity}

The $\lambda_{\max }$ of dye solutions and then change in absorbance were measured before and after treatment by double beam UV-visible spectrophotometer (Hitachi U-2001, Japan).

\section{pH and COD measurement}

The $\mathrm{pH}$ of the solutions was monitored by the $\mathrm{pH}$ meter, while COD was analysed by the open reflux method according to the standard method [23].

\section{FTIR and GC-MS analysis}

The FTIR spectroscopy (Shimadzu U-2001, Japan) and GC-MS (Agilent Technologies 6890N) were conducted at the Pakistan Council for Scientific and Industrial Research (PCSIR), Lahore. The GC-MS analyses were performed to be acquainted with radiolytic end products. The GC having DB-5 capillary column coupled with MS detector through electron impact ionization mode (EI) interface using helium as a carrier gas while mass to charge ratios of frag- ments were determined by ChemStation software and the identified compounds were then compared using software library. Before analyses, the treated samples were extracted, decanted and then dehydrated for further analysis [24, 25].

\section{Conclusion}

The gamma ray-induced degradation of synthetic dyes in the presence of oxidant $\left(\mathrm{H}_{2} \mathrm{O}_{2}\right)$ is a promising, safe and green method beyond the threat of radioactivity. The method has proven to be a best choice in order to remove the colour intensity along with the pollution load in terms of reduction in COD. Complete colour removal with more than $80 \%$ COD reduction has been achieved. The addition of $\mathrm{H}_{2} \mathrm{O}_{2}$ promotes treatment efficiency and not only scavenges the reducing species but also promotes oxidation. The change in $\mathrm{pH}$ of media was insignificant, and degradation efficiency was uniform at all $\mathrm{pH}$ values. The degraded end products were monitored by FTIR and GC-MS studies that revealed that the radiation treatment has mineralized the targeted compound. Furthermore, the treatment may be extended to treat the wastewater of industrial origin.

Acknowledgment. We are very grateful to authorities of PCSIR, Lahore, Pakistan, for providing the facility of FTIR and GC-MS for analysis.

\section{References}

1. Puvaneswari, N., Muthukrishnan, J., \& Gunasekaran, P. (2006). Toxicity assessment and microbial degradation of azo dyes. Ind. J. Exp. Biol., 44(8), 618-626.

2. Muneer, M., Hafiz, N., Usman, M., UR Rehman, F., Saeed, M., Bhatti, H. N., \& Kanjal, M. I. (2015). Environmentally friendly oxidative degradation of reactive orange dye by high energy radiation. Oxid. Commun., 38, 2091-2099.

3. Adedayo, O., Javadpour, S., Taylor, C., Anderson, W. A., \& Moo-Young, M. (2004). Decolourization and detoxification of methyl red by aerobic bacteria from a wastewater treatment plant. World J. Microb. Biotech., 20(6), 545-550.

4. Ollis, D. F., Pelizzetti, E., \& Serpone, N. (1991). Photocatalyzed destruction of water contaminants Environ. Sci. Technol., 25(9), 1522-1529.

5. Ma, H., Wang, M., Yang, R., Wang, W., Zhao, J., Shen, Z., \& Yao, S. (2007). Radiation degradation of Congo Red in aqueous solution. Chemosphere, 68, 1098-1104. 
6. Camp, R., \& Sturrock, P. E. (1990). The identification of the derivatives of C.I. Reactive Blue 19 in textile wastewater. Water Res., 24(10), 1275-1278.

7. Prevot, A. B., Baiocchi, C., Brussino, M. C., Pramauro, E., Savarino, P., Augugliaro, V., Marci, G., \& Palmisano, L. (2001). Photocatalytic degradation of Acid Blue 80 in aqueous solutions containing $\mathrm{TiO}_{2}$ suspensions. Environ. Sci. Technol., 35(5), 971-976.

8. Sugiarto, A. T., Ito, S., Ohshima, T., \& Skalny, J. D. (2003). Oxidative decolouration of dyes by pulsed discharge plasma in water. J. Electrostat., 58(1/2), 135-145.

9. Kalra, S. S., Mohan, S., Sinha, A., \& Singh, G. (2011). Advanced oxidation processes for treatment of textile and dye wastewater: A review. In 2nd International Conference on Environmental Science and Development (Vol. 4, pp. 271-275). Singapore: IACSIT.

10. Liau, L. C. K., \& Chiang, P. I. (2007). Multiple nano$\mathrm{TiO}_{2}$ layers to prevent dye/nano-TiO ${ }_{2}$ from photodegradation under a UV-exposure environment. Appl. Surf. Sci., 253(8), 3982-3986.

11. Munter, R. (2001). Advanced oxidation processes current status and prospects. J. Proc. Est. Acad. Sci., $50,59-80$.

12. Getoff, N. (1999). Radiation chemistry and the environment. Radiat. Phys. Chem., 54(4), 377-380.

13. Duarte, C. L., Sampa, M. H. O., Rela, P. R., Oikawa, H., Cherbakian, E. H., Silveira, C. G., \& Azevedo, A. L. (2002). Advanced oxidation process by electron beam irradiation induced decomposition of pollutants in industrial wastes. Radiat. Phys. Chem., 63(3/6), 647-651.

14. Muneer, M., Adeel, S., Ayub, S., Zuber, M., Rehman, F. U., Kanjal, M. I., Iqbal, M., \& Kamran, M. (2016). Dyeing behaviour of microwave assisted surface modified polyester fabric using disperse orange25: improvement in colour strength and fastness properties. Oxid. Commun., 39(2), 1430-1439.

15. Hosono, M., Arai, H., Aizawi, M., Yamamoto, L., \& Shimizu, K. (1993). Decoloration and degradation of azo-dye in aqueous-solution supersaturated with oxygen by irradiation of high-energy electron-beam. Int. J. Appl. Radiat. Isot., 44, 1199-1203.
16. Solpan, D., \& Guven, O. (2002). Decoloration and degradation of some textile dyes by gamma irradiation. Radiat. Phys. Chem., 65(4/5), 549-558.

17. Ather, M., Iqbal, M., Muneer, M., \& Bhatti, I. A. (2012). Degradation study of reactive Violet 1 by gamma radiation. J. Chem. Soc. Pak., 34(4), 787-792.

18. Daneshvar, N., Rabbani, M., Modirshahla, N., \& Behnajadya, M. A. (2005). Photooxidative degradation of Acid Red 27 in a tubular continuous-flow photoreactor: influence of operational parameters and mineralization products. J. Hazard. Mater., 118(1/3), 155-160.

19. Buxton, G. V., Greenstock, C. L., Helman, W. P., \& Ross, A. B. (1988). Critical review of rate constants for reactions of hydrated electrons, hydrogen atoms and hydroxyl radicals $\left(\cdot \mathrm{OH} / \cdot \mathrm{O}^{-}\right)$in aqueous solutions. J. Phys. Chem. Ref. Data, 17, 513. http://doi. org/10.1063/1.555805.

20. Zhang, S. J., Hu, H. Q., \& Zhao, Y. (2005). Kinetic modeling of the radiolytic degradation of Acid Orange 7 in aqueous solution. Water Res., 39(5), 839-846.

21. Feng, W., Nansheng, D., \& Helin, H. (2000). Degradation mechanism of azo dye C. I. reactive red 2 by iron powder reduction and photooxidation in aqueous solution. Chemosphere, 41(8), 1233-1238.

22. Muneer, M., Bhatti, I. A., Bhatti, H. N., \& Rehman, K. (2011). Applications of advanced oxidation process for industrial wastewater treatment. Asian J. Chem., 23(6), 2392-2394.

23. American Public Health Association. (2005). Standard methods for the examination of water and wastewater (21st ed.), A. D. Eaton, L. S. Clesceri, M. A. H. Franson, A. E. Greenberg, \& E. W. Rice (Eds.). Washington: American Public Health Association.

24. Ozen, A. S., Aviyente, V., \& Klein, R. A. (2003). Modeling the oxidative degradation of azo dyes: A density functional theory study. J. Phys. Chem., 17(24), 4898-4907.

25. Lucarelli, L., Nadtochenko, V., \& Kiwi, J. (2000). Environmental photochemistry: Quantitative adsorption and FTIR studies during the $\mathrm{TiO}_{2}$-photocatalyzed degradation of Orange II. Langmuir, 16(3), 1102-1108. 